Article

\title{
Unmanned Aerial System-Based Data Ferrying over a Sensor Node Station Network in Maize
}

\author{
Jasreman Singh ${ }^{1, * \mathbb{D}}$, Yufeng Ge ${ }^{2}$, Derek M. Heeren ${ }^{2}$, Elizabeth Walter-Shea ${ }^{3}$, Christopher M. U. Neale ${ }^{2,4}$, \\ Suat Irmak ${ }^{5}$ and Mitchell S. Maguire ${ }^{4}$
}

check for updates

Citation: Singh, J.; Ge, Y.; Heeren, D.M.; Walter-Shea, E.; Neale, C.M.U.; Irmak, S.; Maguire, M.S. Unmanned Aerial System-Based Data Ferrying over a Sensor Node Station Network in Maize. Sensors 2022, 22, 1863. https:/ / doi.org/10.3390/s22051863

Academic Editor: Sigfredo Fuentes

Received: 10 February 2022

Accepted: 24 February 2022

Published: 26 February 2022

Publisher's Note: MDPI stays neutral with regard to jurisdictional claims in published maps and institutional affiliations.

Copyright: (C) 2022 by the authors. Licensee MDPI, Basel, Switzerland. This article is an open access article distributed under the terms and conditions of the Creative Commons Attribution (CC BY) license (https:// creativecommons.org/licenses/by/ $4.0 /)$.
1 Department of Biomedical, Biological and Chemical Engineering, University of Missouri, 209 Agricultural Engineering Building, Columbia, MO 65211, USA

2 Department of Biological Systems Engineering, University of Nebraska-Lincoln, Lincoln, NE 68588, USA; yge2@unl.edu (Y.G.); derek.heeren@unl.edu (D.M.H.); cneale@nebraska.edu (C.M.U.N.)

3 School of Natural Resources, University of Nebraska-Lincoln, Lincoln, NE 68588, USA; ewalter-shea1@unl.edu

4 Daugherty Water for Food Global Institute, University of Nebraska, Lincoln, NE 68588, USA; mmaguire2@unl.edu

5 Department of Agricultural and Biological Engineering, Pennsylvania State University, University Park, PA 16802, USA; sfi5068@psu.edu

* Correspondence: js8wg@missouri.edu

\begin{abstract}
Agriculture is considered a hotspot for wireless sensor network (WSN) facilities as they could potentially contribute towards improving on-farm management and food crop yields. This study proposes six designs of unmanned aerial system (UAS)-enabled data ferries with the intent of communicating with stationary sensor node stations in maize. Based on selection criteria and constraints, a proposed UAS data ferrying design was shortlisted from which a field experiment was conducted for two growing seasons to investigate the adoptability of the selected design along with an established WSN system. A data ferry platform comprised of a transceiver radio, a mini-laptop, and a battery was constructed and mounted on the UAS. Real-time monitoring of soil and temperature parameters was enabled through the node stations with data retrieved by the UAS data ferrying. The design was validated by establishing communication at different heights $(31 \mathrm{~m}, 61 \mathrm{~m}$, and $122 \mathrm{~m})$ and lateral distances $(0 \mathrm{~m}, 38 \mathrm{~m}$, and $76 \mathrm{~m})$ from the node stations. The communication success rate (CSR) was higher at a height of $31 \mathrm{~m}$ and within a lateral distance of $38 \mathrm{~m}$ from the node station. Lower communication was accredited to potential interference from the maize canopy and water losses from the maize canopy.
\end{abstract}

Keywords: unmanned aerial systems; wireless communication; crop canopy interference; long-range radios; multi-rotor unmanned aerial system; flight scheduling; data ferry; communication success rate

\section{Introduction}

Wireless communication technology has contributed towards the advancement of precision agriculture by providing alternatives to gather and process information [1] which can improve field crop production efficiency and profitability along with natural resources conservation. The technology has contributed to the implementation of wireless sensor networks (WSNs), a compilation of several nodes, with each node being a low-power and low-cost device equipped with one or more sensors, a processor, memory, a power supply, and a transceiver [2]. Each sensor node communicates wirelessly through a communication link and transmits data to a base station or coordinator node via a gateway.

The feasibility of deploying WSNs at low cost has made these systems highly desirable for military, agriculture, sports, medicine, and industry. The potential applications of WSNs as cost-effective processes to improve agricultural resource management have been reported: irrigation management systems [3], farming systems monitoring [4-6], pest 
and disease control [7], controlled use of fertilizers [8], cattle movement monitoring [9], groundwater quality monitoring [10], greenhouse gases monitoring [11], asset tracking [12], and remote control and diagnosis $[13,14]$. The most promising applications for WSN in precision agriculture are irrigation management, farming monitoring, disease control, and fertilizer accuracy [15]. However, some challenges in WSN applications have been identified such as low battery power, limited computation capability, and sensor node low memory storage $[2,16]$ as well as energy consumption, cost, communication range, optimum deployment schemes, measurement periods, routing protocols, scalability, and fault tolerance [17]. Thus, innovations and creativity in WSN design are needed to be effectively used in agricultural applications.

Unmanned aerial systems (UASs) have been widely used in wireless communication applications because of their high maneuverability and low cost. For an existing WSN, the UAS can be an ideal carrier to form a UAS-based WSN (UWSN). A UAS-based WSN could provide a faster moving speed, longer deployment range, and a relatively longer operating time [18] than WSNs employing other traditional mobile sensor nodes. Recently, the potential scope of a UWSN was identified as a research topic to be investigated for various precision farming applications. Malaver et al. [11] presented the development of a solar-powered UWSN to monitor greenhouse gases (methane and carbon dioxide). Kirichek and Kulik [19] developed analytical and simulation models of a flying ubiquitous sensor network and concluded that such a device is suitable for transferring a small amount of data (transmission rate of 240-280 bits/s) over long distances. Wu et al. [20] investigated the dynamics of uplink and downlink communication using multiple UAS-mounted aerial base stations to serve a ground-based group of users. A rotary-wind UAS-based WSN system for wireless communication was proposed by Zeng et al. [21] and required minimum energy to operate. A remotely piloted unmanned lighter-than-air platform was recently proposed by Gili et al. [22] for the purpose of land use monitoring.

In this study, a UWSN system design is proposed which would comprise hybrid terrestrial surface and sub-surface sensor network stations that communicate with an airborne data ferry deployed on a UAS. Each sensor node station of the network is equipped with three soil water content sensors and one infrared thermometer. The UAS-based data ferrying design is based on criteria and constraints based on the experimental site (research farm) and the nature of the experiment to be conducted. The UAS-based data ferrying system was designed to include wireless technology, a UAS, a radio power source, and memory storage. The major constraints assessing the system were design cost and adoptability.

The design objective was to assemble and test a UAS-enabled data ferrying system that communicates wirelessly with a soil water/crop canopy temperature measurement WSN system with the purpose to monitor soil water content, plant canopy temperature, and air temperature at strategically selected locations across a field in real-time. Six designs based on design objective and constraints were considered and assessed; the best design that met the desired requirements (based on how the system meets the design objective for a field and constraints like that used in this study) was selected and validated in maize over different heights and lateral distances.

\section{Materials and Methods}

\subsection{Proposed UAS Data Ferrying Designs}

\subsubsection{Criteria}

The wireless communication system was designed to develop a communication channel that sufficiently covers the 50-ha research area at the University of Nebraska's Eastern Nebraska Research and Extension Center (ENREC) near Mead, Nebraska. The maximum permissible UAS flight height (as per Federal Aviation Administration) is $122 \mathrm{~m}$ above ground, thus limiting the testing for successful wireless communication to a $122 \mathrm{~m}$ height. Signals between the transceiver (primary) radio and the secondary radio must overlap within their emitted signal footprints to establish communication. Thus, the line of sight (clear communication path) between the transceiver radio and the secondary radio must 
be considered for a typical US mid-west maize farm (area $>50$ ha, i.e., diameter $>800 \mathrm{~m}$ ). In addition, communication depending on the location of the node station radio could be affected by the vegetative canopy itself, which could cause signal propagation absorption, reflection, attenuation, and scattering [23]. Therefore, the desired range of distance between the radios could be approximately $800 \mathrm{~m}$ (considering the size of the farm is $50 \mathrm{ha}$, and UAS is maneuvering at a height of $122 \mathrm{~m}$ ) to establish the communication.

The basic scheme is to retrofit the UAS with a wireless transceiver as a data ferry to retrieve datasets from the wireless sensor network (WSN) as the UAS flies across a typical US mid-west maize field. The design should consider a scalable network size scenario where more radios are needed. The transmission time from each node station for the study field should be approximately two minutes to accommodate the battery charge needed by the UAS while it maneuvers over the sensor node stations and downloads data. Thus, the transmission rate is expected to be a few hundred kilobits per second with the minimum data transfer of approximately $2-3$ megabits per flight since each sensor node station will record measurements from five sensors frequently.

\subsubsection{Constraints}

A primary reason for the slow adoption of precision agriculture technology by producers has been the low rate of return on investment. An opportunity to place low-cost sensors and advanced information systems for improving agricultural operations efficiency, while protecting natural resources (non-destructive installation) will add novelty to the overall objective; a low learning curve and low cost will encourage adoption of the wireless technology by producers/agronomists.

\subsubsection{Design Parameters and Proposed UAS Data Ferrying Designs}

Considering the described design objective, criteria, and constraints, various wireless communication system data ferrying designs were explored based on capabilities, adaptability, and cost of the following factors: (1) wireless technology protocol, (2) UAS, (3) system power source, and (4) data storages.

1. Three wireless technologies designed for industrial/commercial applications that are mostly used for agricultural farm operations were explored for this study: long-range radio (LoRa), ZigBee, and general packet radio service (GPRS). The LoRa protocol was introduced by the LoRa Alliance for the low power and wide-area Internet of Things (IoT) communication associated with the indoor transmission, Pitì et al. [24]. The LoRa gateway can collect data from LoRa nodes to construct the topology of a star network and may communicate with a cloud server over a long communication for high scalability. The LoRa protocol has a wide range of applicability in precision agriculture $[6,25,26]$. Sensor nodes based on the ZigBee wireless protocol in the agricultural field can communicate with a router up to $100 \mathrm{~m}$. Recent studies have employed ZigBee for precision agriculture [27-29] because of its low power consumption, low cost, self-forming characteristics, and suitable communication range. General packet radio service (GPRS)/3G/4G employs packet data (a bit of data that is packaged for transmission) service for GSM-based cellular phones. The GPRS technology communication rates depend on consumer volume where consumers share common communication channels and resources and frequently experience variable delays and throughputs. The sensors could be interfaced to the GPRS system sensor board to obtain and transmit information to the remote server through the GPRS board, which depends on a GSM/GPRS mobile network. Some studies have deployed a GSM/GPRS mobile network for applications in precision agriculture [30-32].

2. Fixed-wing and multi-rotor UAS designs were considered as these are mostly used for agricultural operations. Fixed-wing UAS has a longer flight endurance capacity while multi-rotors can provide for stable and easy vertical take-off and landing [33].

3. The power supply to the wireless communication setup on the UAS could be tethered from the UAS or be powered from an external battery source mounted on the UAS. 
4. Transmitted data could be stored on the memory storage of the UAS or transmitted to the cloud.

It is essential for the system to be cost-effective and adoptable.

Based on these design parameters, six data ferrying communication systems designs (i.e., a combination of wireless technology protocol, UAS, a power source for the system, and data storages) were assessed:

Design A: ZigBee wireless protocol, fixed-wing UAS, power tethered from UAS, cloud memory storage.

Design B: LoRa wireless protocol, multi-rotor UAS, external power source, memory storage over the UAS.

Design C: GPRS wireless protocol, fixed-wing UAS, external power source, memory storage over the UAS.

Design D: ZigBee wireless protocol, multi-rotor UAS, power tethered from UAS, cloud memory storage.

Design E: LoRa wireless protocol, fixed-wing UAS, power tethered from UAS, cloud memory storage.

Design F: GPRS wireless protocol, multi-rotor, external power source, memory storage over the UAS.

The cost-effectiveness and design adoptability of each design was also evaluated.

\subsubsection{Decision Matrix}

Proposed designs were assessed based on the design objective for a typical US midwest maize field (area $>50 \mathrm{ha}$ ), the criteria, and the constraints. The proposed designs were evaluated based on an evaluation matrix where points were allocated to the four criteria, and two constraints. The evaluation results are provided in a matrix (Table 1) with scores for each criterion and constraint explained below:

Table 1. The unmanned aerial systems (UAS) data ferry decision matrix table for six proposed designs based on the four criteria and two constraints with the total points for each design.

\begin{tabular}{|c|c|c|c|c|c|c|c|}
\hline & $\begin{array}{c}\text { Criteria } 1 \\
\text { Wireless Technology }\end{array}$ & $\begin{array}{l}\text { Criteria } 2 \\
\text { UAS }\end{array}$ & $\begin{array}{c}\text { Criteria } 3 \\
\text { Power Supply }\end{array}$ & $\begin{array}{c}\text { Criteria } 4 \\
\text { Data Storage }\end{array}$ & $\begin{array}{c}\text { Constraint } 1 \\
\text { Cost }\end{array}$ & $\begin{array}{l}\text { Constraint } 2 \\
\text { Adoptability }\end{array}$ & Total \\
\hline Design A & 2 & 1 & 1 & 1 & 3 & 3 & 11 \\
\hline Design B & 3 & 2 & 2 & 2 & 4 & 5 & 18 \\
\hline Design C & 1 & 1 & 2 & 2 & 4 & 3 & 13 \\
\hline Design D & 2 & 2 & 1 & 1 & 5 & 5 & 16 \\
\hline Design E & 3 & 1 & 1 & 1 & 3 & 3 & 12 \\
\hline Design F & 1 & 2 & 2 & 2 & 5 & 4 & 16 \\
\hline
\end{tabular}

Criteria 1 (wireless technology): The six wireless technology protocol designs were analyzed and assigned points from 1 to 3 ( 1 being less desirable and 3 being highly desirable). Since the GPRS wireless protocol has a communication range between $1-10 \mathrm{~km}$ and a high-power consumption $(560 \mathrm{~mW})$, the GPRS was assigned a point value of 1 . The ZigBee wireless protocol has a communication range of $100 \mathrm{~m}$ and has lower power consumption $(36.9 \mathrm{~mW})$ but the line-of-sight between the sensor node and the coordinator node must be available, so the potential for canopy interference could be an issue. Thus, the ZigBee wireless protocol was awarded a point value of 2. Because the LoRa wireless protocol has a long range $(5 \mathrm{~km})$ and low power consumption $(100 \mathrm{~mW})$, it was rated at 3 points.

Criteria 2 (UAS): The two UAS systems were evaluated and given points from 1 to 2 (with 2 being the more desirable rating). The fixed-wing UAS was rated 1 out of 2 points because of its limitations of low maneuverability, higher cost, and tedious take-off and landing. The multi-rotor UAS was rated 2 points because of its better maneuverability and more controlled take-off and landing as compared to the fixed-wing UAS. 
Criteria 3 (power supply): The two types of power supplies studied were given points from 1 to 2 . Since the power supply to the wireless communication setup tethered from the UAS could potentially add load on the UAS battery, it was rated 1 out of 2 points. An inexpensive and light external power source mounted on the UAS was determined as a better alternative than tethering the power from UAS since it could sufficiently accommodate the power requirements of the whole system and not add power load to the UAS. Thus, it was assigned 2 points.

Criteria 4 (data storage): Two data storage modes were considered (on-board UAS memory and cloud storage) and awarded points from 1 to 2. Data transmitted over a single flight would be small (around 2 megabits), so cloud storage would not be very helpful in this scenario as it would add unnecessary complexity. Cloud data storage was given 1 out of 2 points, while an on-board UAS memory card was given 2 points.

Constraint 1 (cost): Cost-effectiveness of each system design was evaluated with points ranging from 1-5. Low points were allocated to the design with higher costs. As much as 2 points could be allocated for the cost of the wireless technology protocol, as much as 2 points could be allocated for the UAS cost, and 0 to 1 point for the power source for the wireless communication. The LoRa and ZigBee wireless protocols (allocated 2 points) were low-cost setup systems in comparison to a GPRS wireless protocol (1 point). The fixed-wing UAS is an expensive UAS (allocated 1 point) in comparison to the multi-rotor UAS ( 2 points), in general. Tethering power from the UAS would be economical (allocated 1 point) in comparison to mounting an external battery source ( 0 points) on the UAS.

Constraint 2 (adoptability): Adoptability of the design system was determined based on the application of the system by a producer/crop consultant for agronomic decisionmaking. Points ranging from 1-5 were given to the system based on the adoptability of the system with low points allocated to the design with low adoptability.

'Design B' (LoRa wireless protocol, multi-rotor UAS, external power source, memory storage over the UAS) (Table 1) was selected based on the matrix total points and was subsequently investigated as a suitable UAS data ferrying design for operations with a WSN installed in a typical US mid-west maize field.

\subsection{Field Experiment Description}

A field experiment for testing the proposed UAS data ferrying design was conducted over a nearly 53 ha maize field (typical US mid-west maize field) at the University of $\mathrm{Ne}$ braska's Eastern Nebraska Research and Extension Center (ENREC) near Mead, Nebraska during the 2020 and 2021 growing seasons (Figure 1). Maize was planted in one half of the field and soybean was planted in the other half and was irrigated with a center pivot (Lindsay Corporation Zimmatic 8500). In 2020, the field was planted with soybean in the north half of the field and maize in the southern half. The crops were rotated during the 2021 growing season (soybean in the south, and maize in the north). The study was conducted when the crop was $80 \%$ or more coverage and at late crop physiological reproductive stages during 2020 and from mid to late growing season during 2021 (Table 2).

Table 2. The planting date, the observed vegetative and reproductive growth stage dates for maize during the 2020 and 2021 growing seasons.

\begin{tabular}{cccc}
\hline Maize Growing Season & Planting Date & Vegetative Period & Reproductive Period \\
\hline 2020 & 11 May & 28 May-16 July & 17 July-29 September \\
\hline 2021 & 28 April & 14 May-16 July & 17 July-26 September \\
\hline
\end{tabular}

Stationary sensor node stations comprised of soil water content sensors and infrared radiometer sensors were installed in the maize portion of the field. Four sensor node stations were installed at the beginning of the 2020 growing season and five in 2021. The selected UAS data ferrying design (Design B: LoRa wireless protocol, multi-rotor UAS, external power source, memory storage over the UAS) was constructed and used for wireless communication with the 
stationary sensor node station; soil moisture and canopy temperature data were to be retrieved from each node station during the UAS flight (Figure 2).

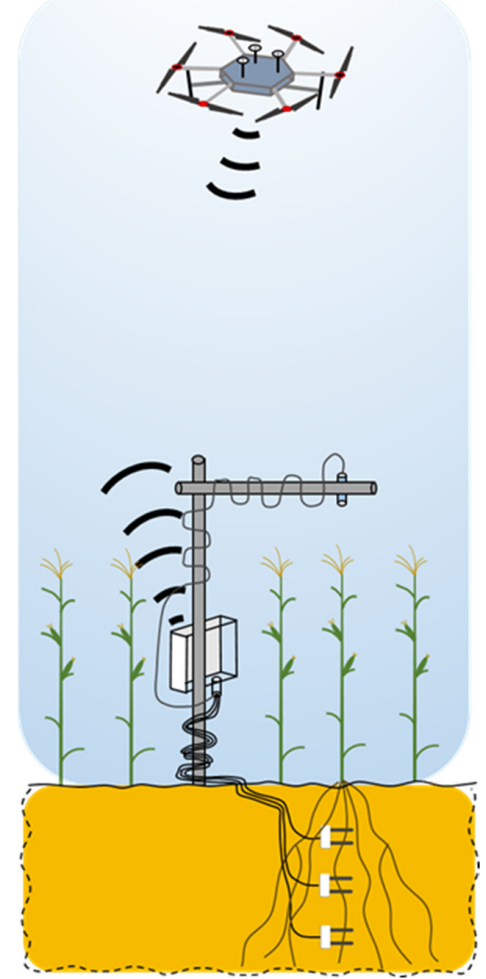

Figure 1. Close-up view of the stationary sensor node station comprising of infrared radiometer and soil water content sensors communicating with an airborne unmanned aerial system-based data ferrying.

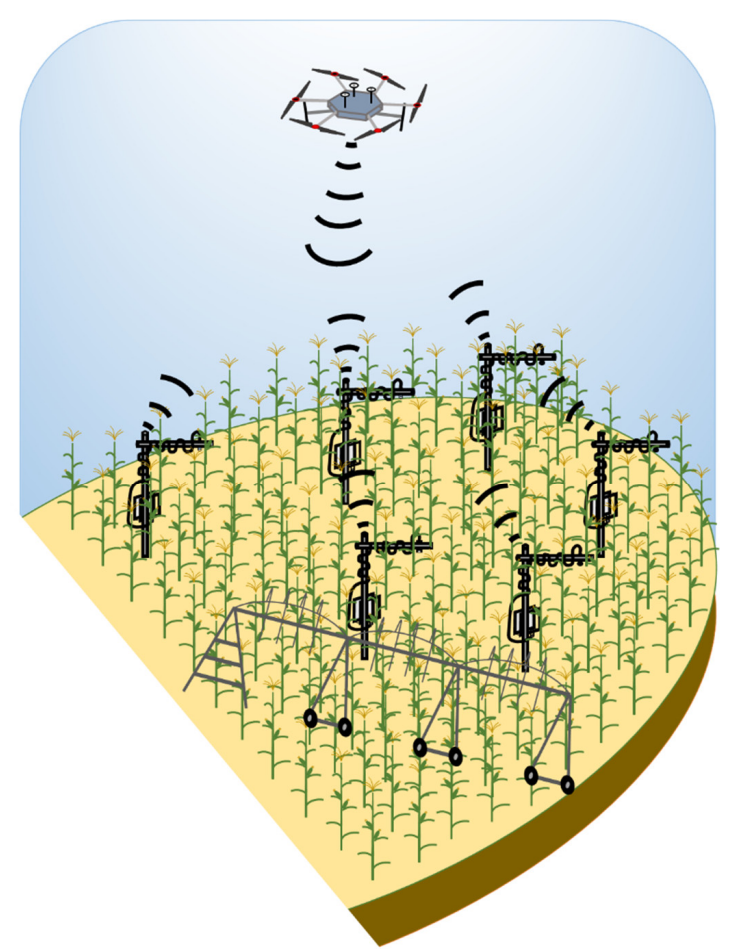

Figure 2. A schematic diagram of airborne based unmanned aerial system data ferry communicating with stationary sensor node stations on the ground installed in maize over a center-pivot irrigated field near Mead, Nebraska. 
During 2020, communication was attempted with the four replicate node stations at UAS hovering heights of $31 \mathrm{~m}, 61 \mathrm{~m}$, and $122 \mathrm{~m}$ above the node stations for three flight days (Figure 3). The UAS hovered at a lateral distance of $0 \mathrm{~m}$ from the node station while the communication attempt was conducted.

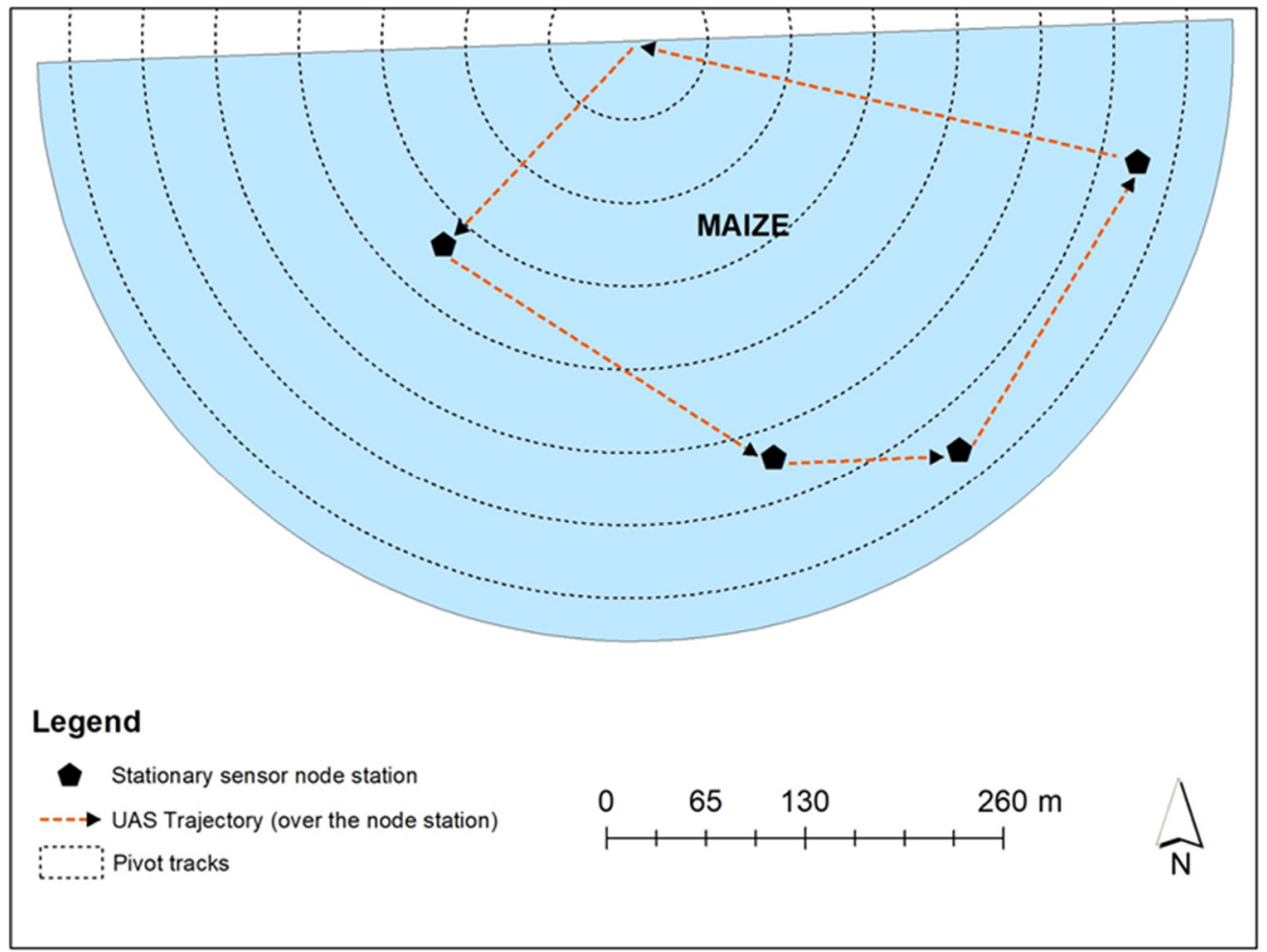

Figure 3. Location of stationary sensor node stations and the trajectory of UAS for four replications during the 2020 growing season. There were three replications of UAS flights that were conducted over the node stations at a height of: (i) $31 \mathrm{~m}$; (ii) $61 \mathrm{~m}$; and (iii) $122 \mathrm{~m}$.

During 2021, communication was attempted with the five replicate node stations at a hovering height of $31 \mathrm{~m}$ above the stations and at lateral distances between the UAS and station of $0 \mathrm{~m}, 38 \mathrm{~m}$, and $76 \mathrm{~m}$ during nine flight days (Figure 4). Signal interference due to crop canopy cover was expected to be maximum from the mid to late growing season of maize.

\subsection{Sensors on the UAS Data Ferry and Node Stations}

\subsubsection{UAS Data Ferry Sensors}

\section{RF 450 Radio}

RF 450 radio (Campbell Scientific, Logan, UT, USA) is a frequency-hopping, spreadspectrum radio that operates within the 902 to $928 \mathrm{MHz}$ license-free bands designed specifically to work along with Campbell Scientific dataloggers. The radio has a maximum link throughput of $115.2 \mathrm{kbps}$. The RF 450 radio offers the advantage of high data transfer speeds along with a low current drain. Wireless network communication over long distances (13-60 miles) could be achieved with this radio based on the antenna and the line-of-sight when no objects interfere with the signal.

In a point-to-multipoint network (multi-point network), the transceiver designated as a primary radio can simultaneously communicate with secondary radios. A multipoint network functions with the primary radio (on the UAS in this study) broadcasting its messages to all secondary radios (radios on the node stations); the secondary radios respond to the primary radio when data from the datalogger are received at the data port. A multi-point network was used to collect data from one-to-many dataloggers and report back to one central site. 


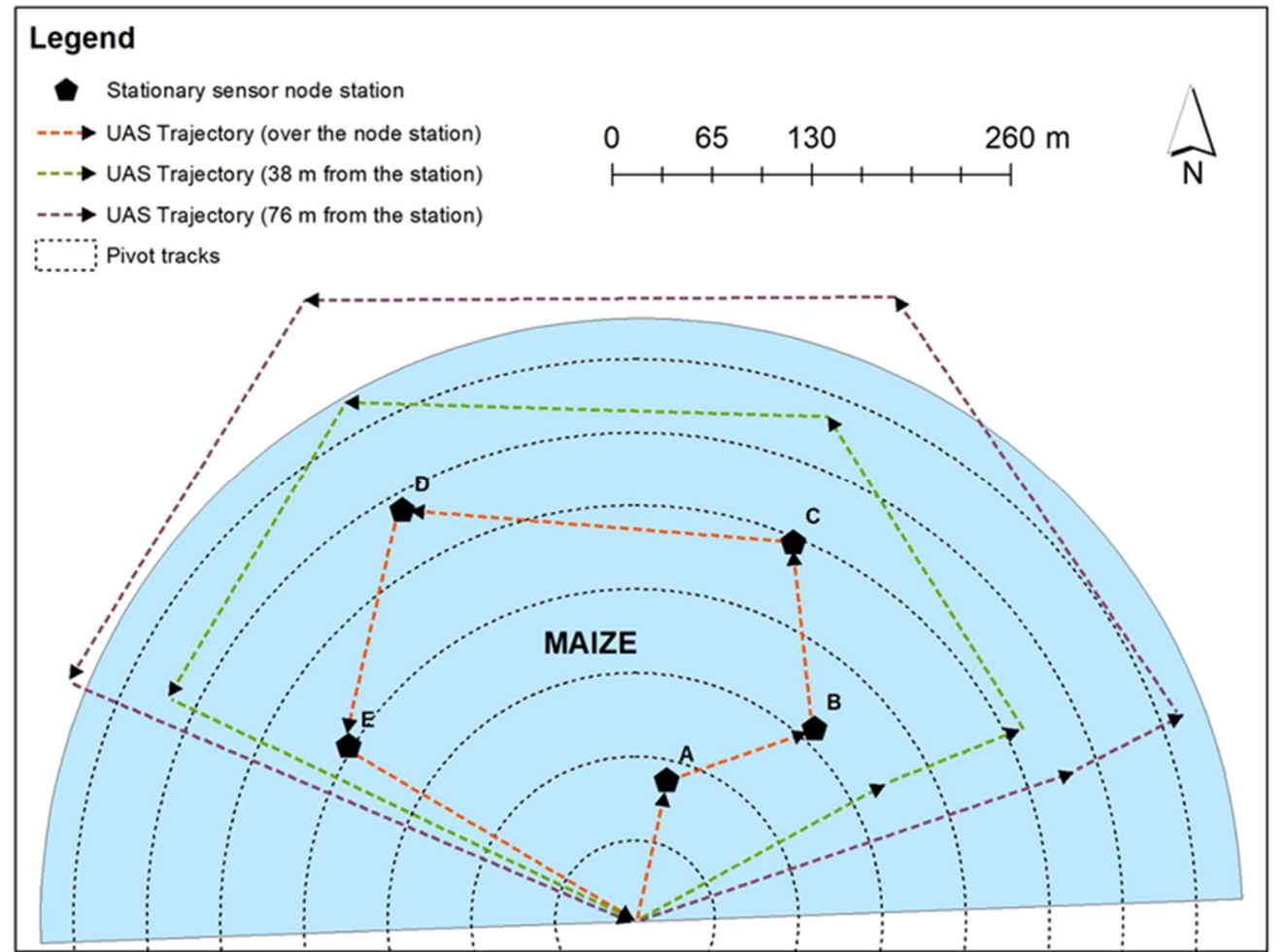

(a)

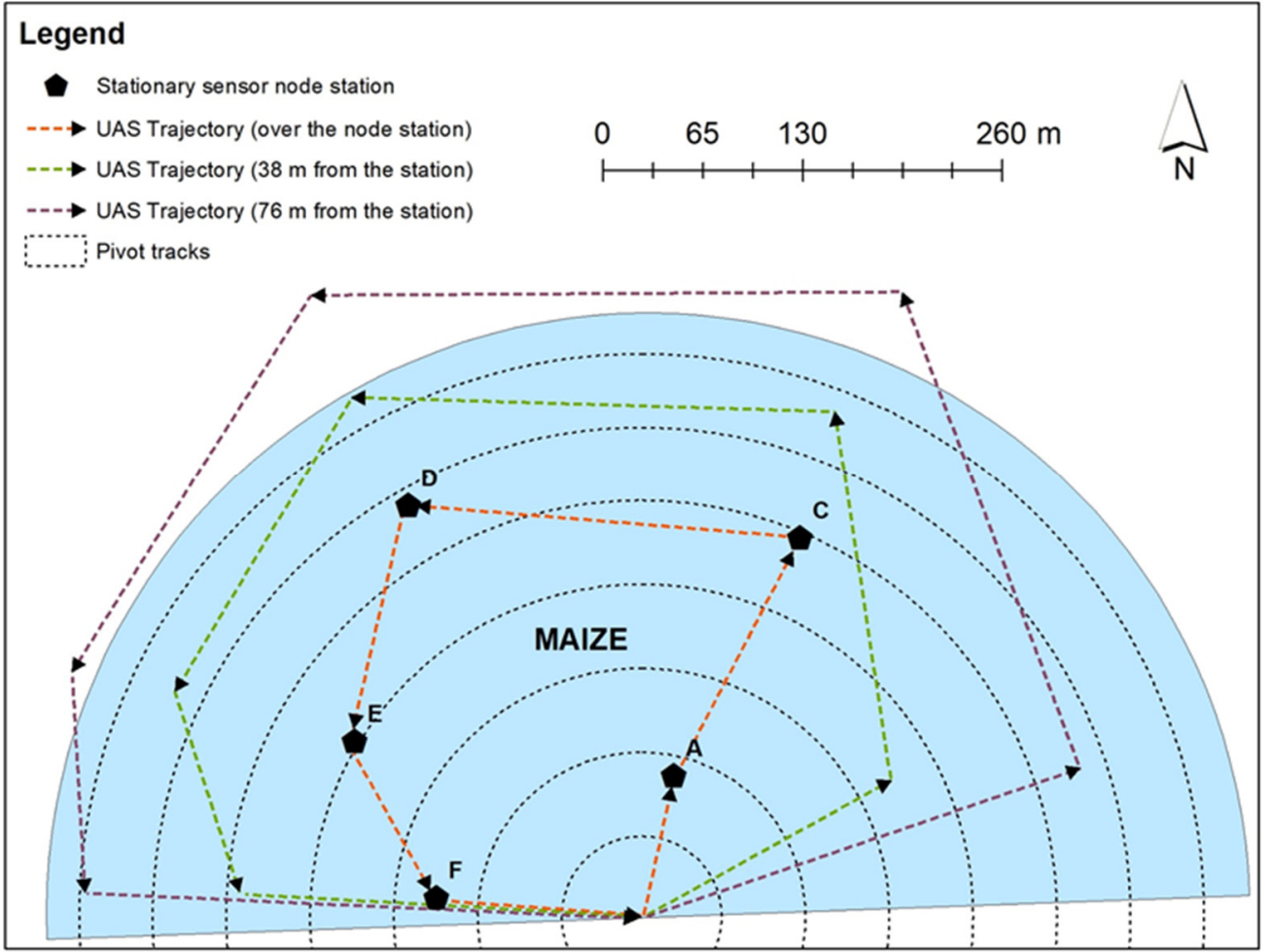

(b)

Figure 4. Location of stationary sensor node stations and the trajectory of UAS for five replications during the 2021 growing season: (a) before the collapse of the station at point ' $\mathrm{B}$ ', and (b) after the installation of the station at point ' $\mathrm{F}$ '. There were three replications of UAS flights: (i) over the station; (ii) $38 \mathrm{~m}$ from the station; and (iii) $76 \mathrm{~m}$ from the station. 
Dipole Omnidirectional Antenna

A $900 \mathrm{MHz}$, dipole, omnidirectional antenna (Product: 15970, Campbell Scientific, Logan, UT: an indoor antenna with a gain value of $1 \mathrm{dBd}$ [decibels relative to a dipole antenna]) was attached to the secondary RF 450 radios at each node station and housed within the datalogger enclosure located within the canopy.

Wave Omnidirectional Antenna

A $900 \mathrm{MHz} 0 \mathrm{dBd}$ 1/2 wave omnidirectional antenna (Product: 14204, Campbell Scientific, Logan, UT, USA) was attached to the primary RF 450 radio mounted on the UAS. The primary antenna has a center frequency of $916 \mathrm{MHz}$ and is equipped with an articulating base that allows the antenna to tilt 90 degrees and rotate 360 degrees, giving flexibility to orient in different directions based on the platform where the antenna is installed (in this study, that is the UAS).

\subsubsection{Node Station Sensors CR1000X Datalogger}

The CR1000X (Campbell Scientific, Logan, UT, USA) datalogger provides measurement and control for a wide variety of applications because of its reliability and ruggedness. Applications include weather stations, mesonet systems, wind profiling, air quality monitoring, hydrological systems, water quality monitoring, and hydrometeorological stations. The electronics of CR1000X are radiofrequency shielded by a unique sealed, stainless-steel canister. The data logger is equipped with a battery-backed clock that assures accurate timekeeping. The secondary RF 450 radio was attached to the CR1000 datalogger in each node station. See Singh, [34] for details of the operation.

\section{GS-1 Soil Water Sensor}

The GS-1 sensor (METER Group Inc., Pullman, WA, USA) was used to measure the soil water content (as described in Singh et al. [35]) every 15 min as an average with a sampling frequency of 5s. It is a recently developed capacitance and frequency domain technologybased sensor with a rugged, durable design configured with two parallel waveguide rods (5.2 $\mathrm{cm}$ in length).

\section{SI-111 Infrared Radiometer}

SI-111 infrared radiometer (Apogee Instruments, Inc., Logan, UT, USA) measures emitted infrared radiation (within an atmospheric window of 8-14 $\mu \mathrm{m}$ ) from which target surface temperature is remotely determined. The infrared radiometer (also known as an infra-red thermometer or IRTs) monitors the maize field surface temperature continuously every $15 \mathrm{~min}$ as an average with a sampling frequency of $5 \mathrm{~s}[36,37]$.

\subsubsection{Unmanned Aerial System (UAS)}

Matrice 600 Pro Hexacopter

The DJI Matrice 600 Pro Hexacopter (DJI, Shenzhen, China), a six-rotor flying platform specifically designed for professional aerial photography, industrial, and research applications, was selected as the multi-rotor UAS for this study (Figure 5a,b). The UAS is equipped with dedicated advanced intelligent flight functions, always ensuring safe and stable operation. The Matrice 600 Pro Hexacopter has a maximum takeoff weight of $15.5 \mathrm{~kg}$ and a patented battery management system to extend flight time and provide a safe and reliable power supply, suitable for the proposed data ferrying application in fields of approximately 50 ha. 


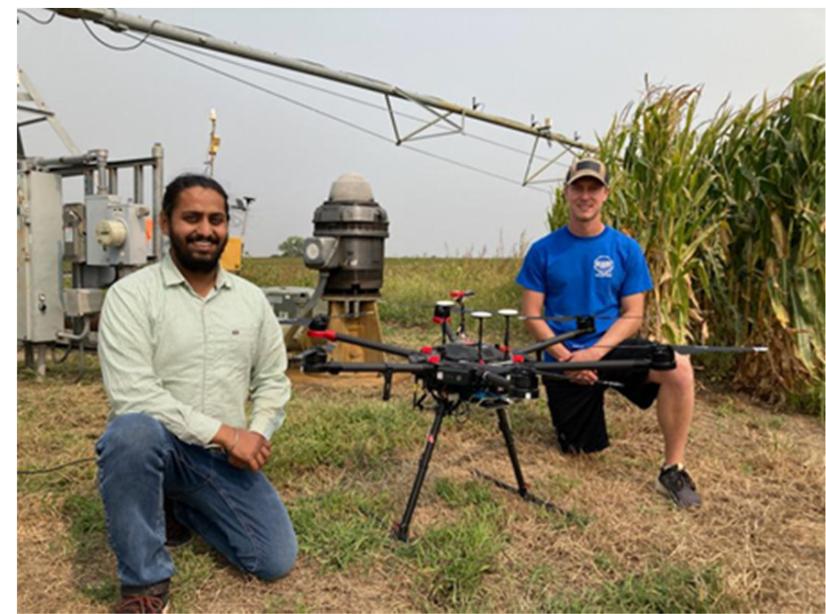

(a)

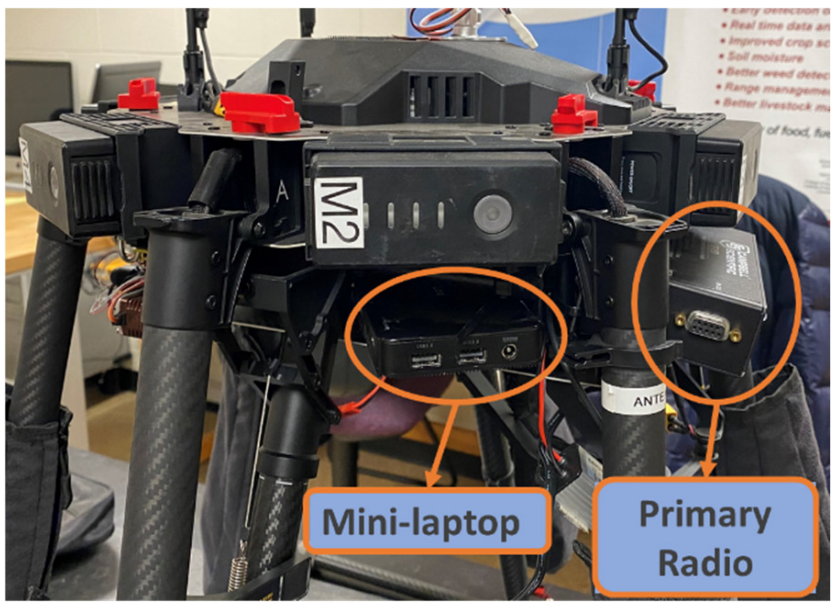

(b)

Figure 5. (a) The Matrice 600 Pro Hexacopter at the research farm; (b) a close-up view of the hexacopter along with the primary radio and the mini laptop.

\subsection{Experiment Design}

The transceiver radio (Campbell Scientific's RF 450 radio) was mounted on the UAS (DJI's Matrice 600 Pro Hexacopter) along with a mini laptop, a battery source (12 V), and an antenna (Campbell Scientific's $900 \mathrm{MHz} 0 \mathrm{dBd}$ 1/2 Wave Omnidirectional antenna) (Figure 5a,b). The mini-laptop and the transceiver radio were powered by a $12 \mathrm{~V}$ battery source. The mini laptop was connected to the primary radio via a USB cable. The antenna was connected to the radio with the antenna oriented downward. The data retrieval from the datalogger to the secondary radio was scheduled using the 'Setup' function of the 'Loggernet 4.5' software (see Singh, [34] for details).

Five node stations were installed in the field (A-E) during the 2021 growing season (Figure 4a). One node station collapsed (the galvanized steel pipe on the tripod supporting sensors and instrumentation was corroded and it snapped) in the middle of the growing season (on 7 August 2021) due to the wind shear of a rainstorm; only two UAS flights were conducted with this station. Another node station was installed as a replacement at point ' $\mathrm{F}^{\prime}$ in the field (Figure $4 \mathrm{~b}$ ); the remaining seven flights were made after the station at location ' $\mathrm{F}$ ' was installed. The sensor node station comprised of a secondary radio (Campbell Scientific's RF 450 radio), an antenna (Campbell Scientific's 900 MHz 1 dBd Omnidirectional antenna), a datalogger (Campbell Scientific's CR1000X datalogger), a battery source (12 V), soil water content sensors (MeterEnvironment's GS-1), and an infrared thermometer (IRT) sensor (Apogee Instruments SI-111, Logan, UT, USA). The secondary radio, the antenna, the datalogger, the battery source, and the wires for soil water content sensors and infrared radiometer were enclosed in an enclosure box (Figure $6 \mathrm{a}, \mathrm{b}$ ). The enclosure box was mounted at a height of $1.5 \mathrm{~m}$ above ground for stations $\mathrm{B}, \mathrm{D}$, and $\mathrm{E}$, and $0.6 \mathrm{~m}$ above the ground for stations $\mathrm{A}$ and $\mathrm{C}$ during the first two experimental trials. During the third experimental trial in 2020, all the enclosure boxes were mounted at a height of $1.5 \mathrm{~m}$ above the ground. The location of the enclosure box places the antenna within the canopy when the maize is at full height. The secondary radio was connected to the datalogger via a null modem cable. The soil water content sensors were inserted at a depth of $0.15 \mathrm{~m}, 0.46 \mathrm{~m}$, and $0.76 \mathrm{~m}$, respectively. The IRT sensor was mounted at a constant height of $1 \mathrm{~m}$ above the maize canopy consistently throughout the growing season. All node station sensors were connected to the datalogger. The output from the sensors was recorded at a $5 \mathrm{~s}$ sampling frequency and averaged every $15 \mathrm{~min}$. 


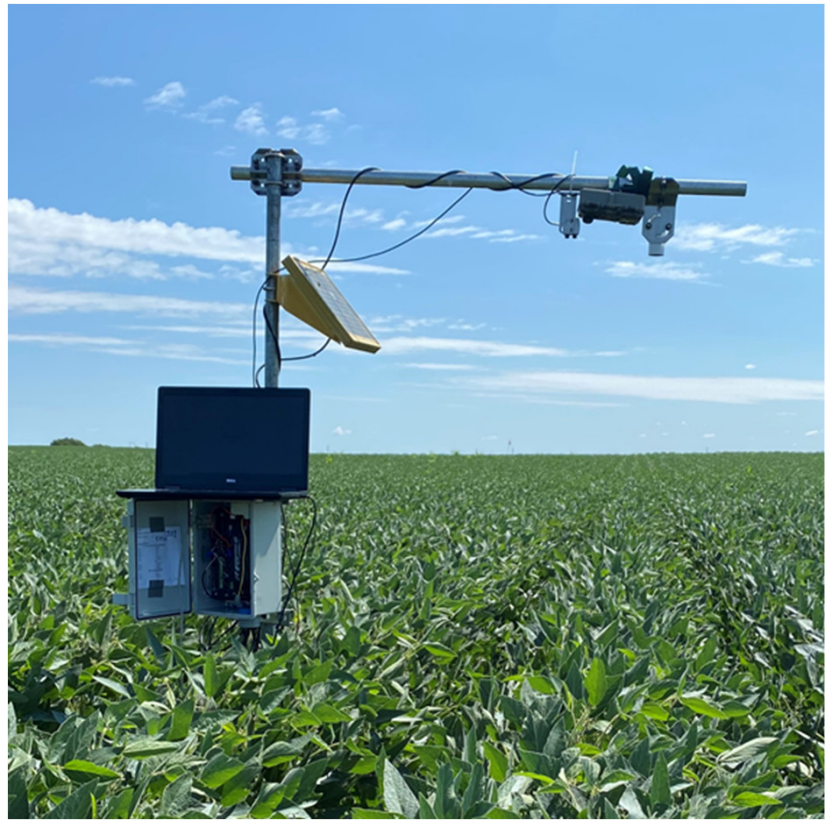

(a)

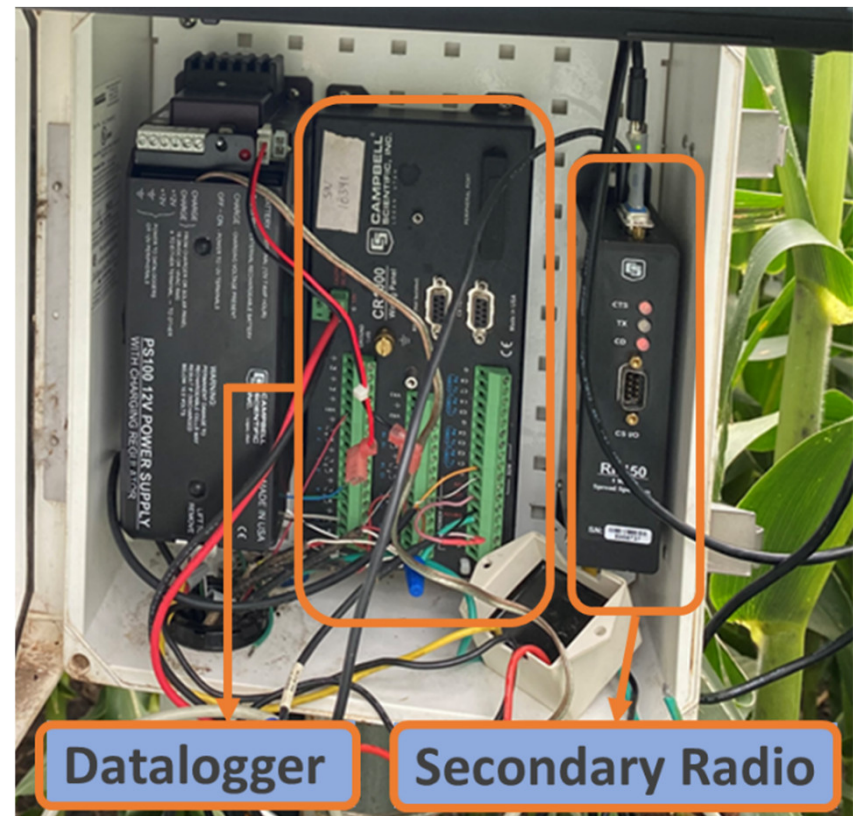

(b)

Figure 6. (a) Sensor node station comprising of infrared radiometer sensor sensing the crop canopy; (b) the layout of the datalogger along with the secondary radio and the power battery source.

Soil moisture, canopy temperature, and air temperature data were transmitted from the datalogger through the secondary RF450 radio to the transceiver (primary) RF450 radio mounted on the UAS. Communication success and data transmission and receipt were assessed at different UAS heights ( $31 \mathrm{~m}, 61 \mathrm{~m}$, and $122 \mathrm{~m}$ above the ground) in 2020, and at different lateral distances of the UAS from the node stations $(0 \mathrm{~m}, 38 \mathrm{~m}$, and $76 \mathrm{~m})$ at a height of $31 \mathrm{~m}$ above the ground in 2021.

Communication success was quantified in terms of CSR (in \%). The CSR for each treatment and each trial day was calculated as:

$$
\operatorname{CSR}(\text { in } \%)=\frac{\mathrm{N}_{\text {established }}}{\mathrm{N}_{\text {attempted }}} \times 100
$$

where CSR is communication success rate, $\mathrm{N}_{\text {established }}$ is the number of replications where the communication was established, and $\mathrm{N}_{\text {attempted }}$ is the number of replications where communication was attempted.

Wireless communication and data retrieval on the UAS data ferry was scheduled via the UAS-mounted mini laptop. Data retrieval between the UAS mini laptop was scheduled before the UAS flight using the unique PakBus address associated with the CR1000X datalogger of each sensor node station. While the UAS was in the line of sight of a sensor node station, the UAS data ferry transceiver radio (which was connected to the mini laptop) would contact and establish wireless communication with the nearby sensor node station secondary radio. The UAS was scheduled to take one minute to fly from the start point to station ' $\mathrm{A}$ ' where it would establish wireless communication with the sensor node station secondary radio and download data within a minute before moving to the next station (station ' $\mathrm{B}$ '), where it would repeat the contact, wireless communication, and data retrieval protocol for each node station until the UAS returned to the start point (Figure 4a). Given the time required for the UAS to fly from one node station to another (approximately $1 \mathrm{~min}$ each) and the time required to retrieve data from a sensor node station when the UAS maneuvers over the station (approximately $1 \mathrm{~min}$ ), the entire data collection by the UAS data ferry from start to finish took $9 \mathrm{~min}$ in 2020 with four node stations and 11 min in 2021 with five node stations. 


\section{Results}

Soil moisture and crop canopy temperature data from stationary sensor node stations were transmitted from the secondary radio (which was linked to the node station datalogger) to the UAS data ferry transceiver radio (which was connected to the UAS data ferry mini laptop). The seven-day data file retrieved from each sensor node station was around 0.3-0.4 megabytes (MB) in size and took approximately one minute to retrieve. Each dataset retrieval was comprised of around 10,000 values (soil water content at three depths, crop canopy, and air temperatures were reported once every $15 \mathrm{~min}$ ). To accommodate data retrieval and the approximate one minute for the UAS to maneuver from one sensor node location to another, the data retrieval from each sensor node station was scheduled two minutes after the previous sensor node station.

Three UAS data ferrying experimental trial events were held during the 2020 growing season (September 2, September 16, and September 30). The UAS flights were conducted at two to three UAS heights $(31 \mathrm{~m}, 61 \mathrm{~m}$, and $122 \mathrm{~m})$, with the four sensor node stations installed in the maize. Communication was attempted during the experimental trial events. The maize crop was at the early denting growth stage on the first experimental trial event/flight day (Table 3). However, for the second and third flight days, the maize was 75\% past denting reproductive stage (R5.75), and at physiological maturity. A 100\% CSR was observed at $31 \mathrm{~m}$ above the ground for all attempts (Table 4) but not for the other UAS heights. Therefore, the $31 \mathrm{~m}$ height was used in investigating the effect of crop canopy interference on radio communication along different lateral distances $(0 \mathrm{~m}, 38 \mathrm{~m}$, and $76 \mathrm{~m})$ from the stationary sensor node stations during the 2021 growing season.

Table 3. UAS flight dates and associated maize physiological growth stages during 2020 and 2021 growing seasons.

\begin{tabular}{cccc}
\hline \multicolumn{2}{c}{ 2020 Growing Season } & \multicolumn{2}{c}{ 2021 Growing Season } \\
\hline Flight Date & $\begin{array}{c}\text { Physiological } \\
\text { Growth Stage }\end{array}$ & Flight Date & $\begin{array}{c}\text { Physiological } \\
\text { Growth Stage }\end{array}$ \\
\hline September 2 & R5.3 & July 27 & R1 (silking) \\
September 16 & R5.75 & July 30 & R2 (early blister) \\
September 29 & R6 & August 21 & R5.1 (early dent) \\
& & August 24 & R5.2 \\
& & August 25 & R5.25 \\
& & September 4 & R5.5 \\
& & September 6 & R5.55 \\
& & September 8 & R5.6 \\
\hline
\end{tabular}

Table 4. The communication success rate (CSR) (in \%) for three treatments (31 m, $61 \mathrm{~m}$, and $122 \mathrm{~m}$ above the ground) during the 2020 growing season in maize.

\begin{tabular}{cccc}
\hline & \multicolumn{3}{c}{ CSR (in \%) during 2020 Growing Season in Maize } \\
\hline Flight Date & $\mathbf{3 1} \mathbf{~ m}$ above Ground & $\mathbf{6 1} \mathbf{~ m}$ above Ground & $\mathbf{1 2 2} \mathbf{~ m}$ above Ground \\
\hline September 2 & $100 \%$ & - & $25 \%$ \\
September 16 & $100 \%$ & $50 \%$ & $50 \%$ \\
September 30 & $100 \%$ & $75 \%$ & $75 \%$ \\
\hline
\end{tabular}

Nine experimental trial events were conducted during the 2021 growing season; the first two events were conducted before the collapse of the station at point ' $\mathrm{B}$ ' on 7 August 2021 (Figure 4a) in the field, and the remaining seven events were conducted after the installation of the station at point ' $F$ ' (Figure $4 \mathrm{~b}$ ) in the field. During the first two events, the maize was in the initial physiological reproductive stages (silking and early-blister, i.e., R1 and R2; Table 3), while the maize was in various phases of dent stage R5 (Table 3) for the remaining seven events. The CSR for the first two trials was $100 \%$ when the UAS (at a 
height of $31 \mathrm{~m}$ ) was directly over the node stations ( $0 \mathrm{~m}$ lateral distance) and $38 \mathrm{~m}$ laterally away from node stations; the CSR was within 40-60\% when the UAS was 76 m laterally away from node stations (at a height of $31 \mathrm{~m}$ ) (Figure 7). The next four trials were conducted during the late reproductive stages of maize (early to mid-denting, i.e., R5.1-R5.4; Table 3), and the CSR was within $40-80 \%$ when the UAS was over the node stations, $60 \%$ when the UAS was $38 \mathrm{~m}$ laterally away from the stations, and within 20-60\% when the UAS was $76 \mathrm{~m}$ laterally away from the node stations. For the last three experimental trial events (around the mid-denting reproductive stage and beyond, i.e., R5.5-R5.6; Table 3), the CSR for all three lateral distances was 100\% (Figure 7).

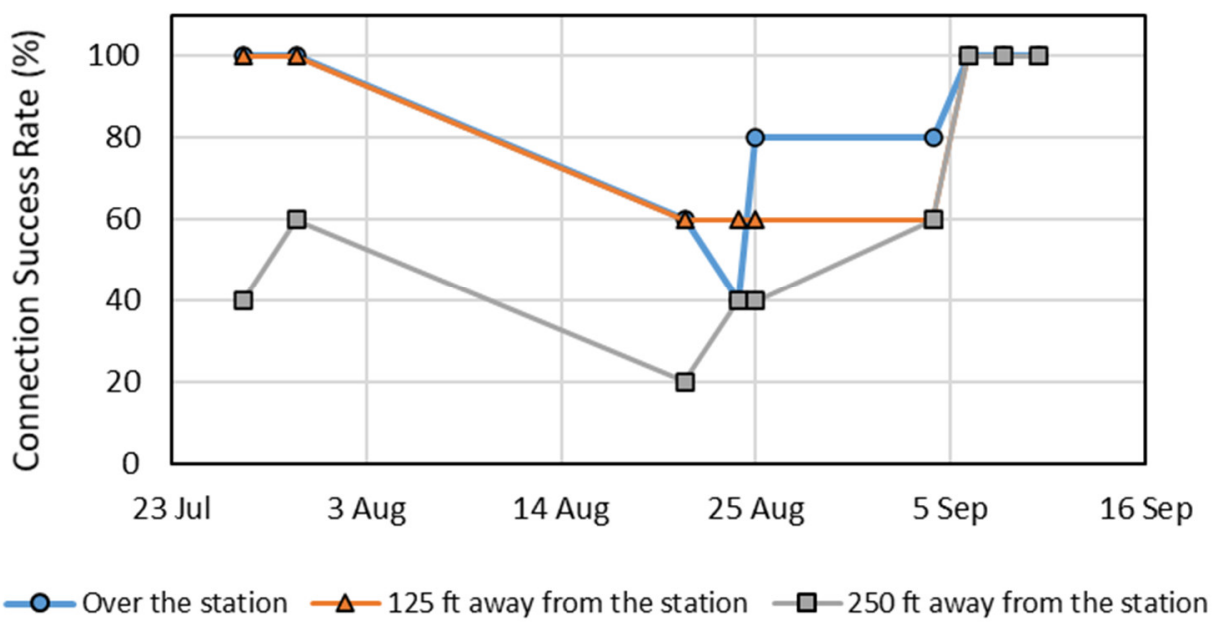

Figure 7. The CSR (in \%) for the five replications of secondary radios communicating with the primary radio mounted on the UAS for three treatments during the 2021 growing season. The UAS maneuvered at a height of $31 \mathrm{~m}$ above the ground at a lateral distance of: (i) $0 \mathrm{~m}$ from (over) the sensor node station; (ii) $38 \mathrm{~m}$ from the sensor node station; and (iii) $76 \mathrm{~m}$ from the sensor node station.

\section{Discussion}

Wireless communication applications in sensor networks in an agriculture setting are still at an early stage of development, and it is already contributing towards the improvement of agricultural management practices. The agricultural sector will be highly benefited by the Internet of Things (IoT) technologies as the management and analysis of IoT data could potentially be used to automate processes, predict situations, and improve agricultural management activities in real-time [38]. In addition, the scope of IoT has increased recently in agricultural activities such as farming, planting, and animal rearing [17,39]. The current study proposes a UAS-enabled data ferrying system that uses narrow band-internet of things technology, i.e., the LoRa (long-range radio) technology, as a means of monitoring water and plant status in an agricultural setting, building on previously published work on the real-time monitoring and calibration of soil water content sensor [35]; and developing inter-relationships between soil water depletion and crop canopy temperature differential [36], and; sensor-based irrigation management of maize and soybean [37]. The LoRa and ZigBee technology offer various advantages such as lower power consumption and data transmission over longer distances in comparison to other wireless technologies or protocols used in agricultural applications, such as WiFi, Bluetooth, GPRS/3G/4G, and SigFox [23]. The comparison indicated that ZigBee and LoRa wireless protocols are more convenient for agricultural applications because of their low power consumption, a suitable communication range for ZigBee, and a long-range communication range for LoRa. For the UAS data ferrying system proposed in the study, LoRa wireless protocol was used considering potential interference from the maize canopy. Similarly, Mahmoud and Mohamad [40] demonstrated that LoRa is a good candidate for low-power and point connectivity for longer distances amongst other wireless communication techniques. Wixted et al. [41] evaluated the performance of LoRa technologies for indoor and outdoor settings, and 
across physical layers (a mix of newer concrete, glass, and sandstone buildings) wireless and multi-gateway wide area networks and found the technology can provide a reliable link for low-cost remote sensing applications.

The real-time information on soil water and plant canopy temperature status using wireless communication could be highly valuable for farmers who do not have access to weather information due to electricity limitations or limited media access. The low power and LoRa wireless sensor networks can be transmitted to cloud platforms for both private and public networks to facilitate optimal resource utilization and real-time data accessibility from everywhere.

The optimal data transmission rate for the network architecture in this study was $240-480$ bits/s, and the LoRa technology's sizable hardware implementation makes it very suitable for the UAS data ferrying designed in this study. With the proposed data ferrying design (using LoRa wireless protocol, multi-rotor UAS, external power source, memory storage over the UAS), the size of data transmitted from the stationary node station was approximately $4000-5000$ bits in one minute. The study by Kirichek and Kulik [19] and Reda et al. [42] confirms the suitability of the LoRa technology.

In this study, commercially available LoRa-based radios were used for wireless communication in a UAS-enabled data ferry WSN (UWSN) in a maize field during the late reproductive growth stages. The CSR for the radios was at 100\% when the UAS maneuvered at a height of $31 \mathrm{~m}$ above the ground; the CSR was lower when the UAS was at heights of 61 and $122 \mathrm{~m}$. During the mid to late growing season when the maize plants were in the early R5 stages, a lower CSR (20-60\%; average 60\%) occurred when the lateral distance between the UAS and the stationary sensor node station was at $76 \mathrm{~m}$. The lower CSR was attributed to interference from the maize crop canopy; radio frequencies are attenuated by water [43] and it is assumed that the radio communication has higher interference from moisture in the vegetation. The average maize plant moisture content changes from $60 \%$ to $30 \%$ at denting stage (R5), and physiological maturity stage (R6), respectively [44]. Eventually, when a substantial amount of water was lost with lower green biomass around the mid-denting stage, the CSR increased (around 100\% for all three lateral distance treatments). Antenna placement within the enclosure which is embedded in the canopy could potentially be an issue contributing to the lower CSR during the maize denting stage and needs to be further researched to potentially strengthen communication possibilities.

The UAS data ferrying design recommended, based on the established criteria uses LoRa wireless protocol, multi-rotor UAS, external power source, and memory storage; the measurement protocol recommended within a UWSN using this data ferry is to have the UAS maneuvering at $31 \mathrm{~m}$ above the ground and close to the stationary sensor node station (lateral distance of $0 \mathrm{~m}$ to $38 \mathrm{~m}$ ) to establish excellent communication and data retrieval. Thus, a UWSN based on the design proposed here could be used by a producer or farmer to monitor in near real-time soil water and plant status to help farmers make agronomic decisions to increase their agricultural productivity. The proposed approach of UAS enabled data ferrying based wireless communication also could be deployed for public, private, or industrial IoT applications in irrigation management systems, farming systems monitoring, pest and disease control, cattle movement monitoring, groundwater quality monitoring, greenhouse gases monitoring, asset tracking, and remote control and diagnosis.

Since UAS and UAS-related technology have only recently developed and are currently evolving at a fast pace, the technology has not been widely applied for developing UWSN systems. Unexpected problems in this study had to be addressed while developing, troubleshooting, and fine-tuning the technology and procedures used to retrieve data from the maize field. System components such as the connector cable (with thin insulation) connecting the mini-laptop and the radio on the UAS would detach occasionally during the flight, due to air resistance from the wind created while the UAS spinning blades would push the air down during takeoff. The issue was resolved by replacing the initial connector cable with a connector cable with thick insulation that did not detach from the radio as it was heavier and was unaffected by air resistance. Weather elements can take a 
toll on equipment. Backup equipment and additional replications should be considered in planning for potential setbacks. One of the stationary sensor node stations collapsed (the galvanized steel pipe on the tripod supporting sensors and the instrumentation was possibly corroded and snapped due to the wind shear of a rainstorm in the middle of the growing season (7 August 2021). The station was removed from the study and replaced by a new stationary sensor node station using the radio which was still operable. The new location meant that the data retrieval scheduling on the primary radio had to be revised and ready for the next flight (the flight route and time allocated for maneuvering from one station to another, and data retrieval).

In general, the technology related to the application of UAS as a platform for data ferrying (flying, integrating wireless communication devices, or retrieving datasets while flying) is a rather novel approach with additional work needed to design and evaluate the entire UWSN system (from node stations to UAS based data ferry). While the main purpose of the UWSN system was meant to perform real-time monitoring of soil moisture and crop canopy temperature for the purpose of irrigation management, significant time was spent developing, troubleshooting, and fine-tuning the technology and procedures used to retrieve the datasets. The methodology adopted in this study could be replicated/run on a testing framework such as FlockAI to investigate the result reproducibility of this experiment [45]. Future research should aim to investigate the scalability and adoptability of the proposed data ferrying system to strengthen the applicability of the UAS data ferrying system. The feasibility of mounting additional advanced instrumentation to the existing design of a data ferrying system for simultaneously capturing thermal/multispectral imagery could also be explored as it would aid in efficient irrigation and agronomic decision-making.

\section{Summary and Conclusions}

Six designs of UAS-enabled data ferrying systems with IoT-enabled communication using radios were proposed based on design criteria and constraints. A final design of a data ferry was selected which comprised of a long-range radio wireless communication protocol, an external power source, a multi-rotor UAS, and memory storage. The selected design of the UAS data ferry was tested over a WSN in a maize field in eastern Nebraska during the latter portions of the 2020 and 2021 growing seasons. Each stationary sensor node station installed in maize contained three soil water content sensors, one infrared radiometer, and one secondary radio. CSR at various UAS heights above the stationary nodes (in 2020) and lateral distance (in 2021) from the nodes was investigated. Three experimental trials during the 2020 growing season demonstrated that a $100 \%$ CSR occurred when the UAS maneuvered directly over the node station at a height of $31 \mathrm{~m}$ above the ground. Henceforth, the UAS was flown at a height of $31 \mathrm{~m}$ above the ground during the 2021 growing season to investigate the effect of lateral distance of the UAS data ferrying from the node station on the CSR. For the nine experimental trial events (flight days) during the 2021 growing season, the CSR was higher (80\% average) when the UAS was directly over the node station ( $0 \mathrm{~m}$ lateral distance) and at a lateral distance of $38 \mathrm{~m}$ from the node station. The CSR was lower when the UAS was $76 \mathrm{~m}$ laterally away from the node station $(60 \%$ average). In general, the lower CSR at higher heights and further distances from the node station was potentially due to the interference from the maize canopy and plant moisture and the location of the antenna in the enclosure; during late reproductive physiological stages when plant water is lower a higher CSR was achieved for all lateral distances as the crop progressed to physiological maturity.

Substantial progress was made in understanding the UAS-based data ferrying system and the potential of the UWSN system to improve agronomic decision making. Future studies to investigate the scalability, adoptability, and optimum deployment scheme (along with mounting an RGB-infrared imaging camera for aid in agronomic decision making, and antenna location) for the proposed data ferrying design could strengthen the applicability of the UWSN system. 
Author Contributions: Conceptualization, J.S., Y.G. and D.M.H.; Methodology, J.S. and M.S.M.; Validation, J.S., Y.G., D.M.H., C.M.U.N., E.W.-S. and S.I.; Formal Analysis, J.S.; Investigation, J.S., Y.G., C.M.U.N. and D.M.H.; Resources, C.M.U.N., D.M.H. and Y.G.; Data Curation, J.S.; Writing-Original Draft Presentation, J.S.; Writing-Review and Editing, E.W.-S., Y.G., M.S.M. and D.M.H.; Supervision, Y.G. and D.M.H.; Project Administration, C.M.U.N., D.M.H. and Y.G.; Funding Acquisition, C.M.U.N., Y.G. and D.M.H. All authors have read and agreed to the published version of the manuscript.

Funding: The funding for this research was provided by a grant from the USDA NIFA Agricultural and Food Research Initiative (Award Number 2017-67021-26249) and the Daugherty Water for Food Global Institute at the University of Nebraska. Additional support was received from the Hatch Act (USDA NIFA, Accession Number 1009760) and the Department of Biological Systems Engineering at the University of Nebraska-Lincoln.

Institutional Review Board Statement: Not applicable.

Informed Consent Statement: Informed consent was obtained from all subjects in the study.

Data Availability Statement: Data is contained within the article. No additional data was created or analyzed in the study.

Acknowledgments: The authors thank Wayne Woldt, Geng Bai, and Burdette Barker for input in the experimental design; Suresh Pradhyun Kashyap for reviewing the manuscript; Alan L. Boldt, Eric Wilkening, Suresh Pradhyun Kashyap, and Sandeep Bhatti for assistance with the data collection; and Mark Schroeder and his team from the University of Nebraska's Eastern Nebraska Research and Extension Center for their cooperation and help with field operations. Weather data were provided by the Nebraska Mesonet and the Nebraska State Climate Office through the High Plains Regional Climate Center. The authors would like to thank the support from the Daugherty Water for Food Global Institute, University of Nebraska.

Conflicts of Interest: The mention of trade names or commercial products is for the information of the reader and does not constitute an endorsement or recommendation for use by the University of Nebraska-Lincoln or the authors. The authors declare no conflict of interest.

\section{References}

1. Behzadan, A.; Anpalagan, A.; Woungang, I.; Ma, B.; Chao, H.-C. An Energy-Efficient Utility-Based Distributed Data Routing Scheme for Heterogenous Sensor Networks. Wirel. Commun. Mob. Comput. 2015, 16, 421-430. [CrossRef]

2. Yick, J.; Mukherjee, B.; Ghosal, D. Wireless Sensor Network Survey. Comput. Netw. 2008, 52, 2292-2330. [CrossRef]

3. Adamala, S.; Raghuwanshi, N.S.; Mishra, A. Development of Surface Irrigation Systems Design and Evaluation Software (SIDES). Comput. Electron. Agric. 2014, 100, 100-109. [CrossRef]

4. Camilli, A.; Cugnasca, C.E.; Saraiva, A.M.; Hirakawa, A.R.; Corrêa, P.L.P. From Wireless Sensors to Field Mapping: Anatomy of an Application for Precision Agriculture. Comput. Electron. Agric. 2007, 58, 25-36. [CrossRef]

5. Kim, Y.D.; Yang, Y.M.; Kang, W.S.; Kim, D.K. On the Design of Beacon Based Wireless Sensor Network for Agricultural Emergency Monitoring Systems. Comput. Stand. Interfaces 2014, 36, 288-299. [CrossRef]

6. Siddique, A.; Prabhu, B.; Chaskar, A.; Pathak, R. A Review on Intelligent Agriculture Service Platform with Lora Based Wireless Sensor Network. Int. Res. J. Eng. Technol. 2019, 100, 2539-2542.

7. Bhargava, K.; Kashyap, A.; Gonsalves, T.A. Wireless Sensor Network Based Advisory System for Apple Scab Prevention. In Proceedings of the 2014 20th National Conference on Communications, NCC, Kanpur, India, 28 February-2 March 2014.

8. Gonçalves, L.B.L.; Costa, F.G.; Neves, L.A.; Ueyama, J.; Zafalon, G.F.D.; Montez, C.; Pinto, A.S.R. Influence of Mobility Models in Precision Spray Aided by Wireless Sensor Networks. In Proceedings of the Journal of Physics, Yokohama, Japan, 26-30 May 2014; Conference Series; IOP Science: Bristol, UK, 2014; Volume 574.

9. Kwong, K.H.; Wu, T.T.; Goh, H.G.; Sasloglou, K.; Stephen, B.; Glover, I.; Shen, C.; Du, W.; Michie, C.; Andonovic, I. Practical Considerations for Wireless Sensor Networks in Cattle Monitoring Applications. Comput. Electron. Agric. 2012, 81, 33-44. [CrossRef]

10. Zia, H.; Harris, N.R.; Merrett, G.V.; Rivers, M.; Coles, N. The Impact of Agricultural Activities on Water Quality: A Case for Collaborative Catchment-Scale Management Using Integrated Wireless Sensor Networks. Comput. Electron. Agric. 2013, 96, 126-138. [CrossRef]

11. Malaver, A.; Motta, N.; Corke, P.; Gonzalez, F. Development and Integration of a Solar Powered Unmanned Aerial Vehicle and a Wireless Sensor Network to Monitor Greenhouse Gases. Sensors 2015, 15, 4072-4096. [CrossRef]

12. Misra, S.; Singh, S. Localized Policy-Based Target Tracking Using Wireless Sensor Networks. ACM Trans. Sens. Netw. 2012, 8, 1-30. [CrossRef] 
13. Coates, R.W.; Delwiche, M.J.; Broad, A.; Holler, M. Wireless Sensor Network with Irrigation Valve Control. Comput. Electron. Agric. 2013, 96, 13-22. [CrossRef]

14. Morais, R.; Fernandes, M.A.; Matos, S.G.; Serôdio, C.; Ferreira, P.J.S.G.; Reis, M.J.C.S. A ZigBee Multi-Powered Wireless Acquisition Device for Remote Sensing Applications in Precision Viticulture. Comput. Electron. Agric. 2008, 62, 94-106. [CrossRef]

15. Garlando, U.; Bar-On, L.; Avni, A.; Shacham-Diamand, Y.; Demarchi, D. Plants and Environmental Sensors for Smart Agriculture, an Overview. Proc. IEEE Sens. 2020, 2020, 2020-2023. [CrossRef]

16. Akyildiz, I.F.; Kasimoglu, I.H. Wireless Sensor and Actor Networks: Research Challenges. Ad Hoc Netw. 2004, 2, 351-367. [CrossRef]

17. Ojha, T.; Misra, S.; Raghuwanshi, N.S. Wireless Sensor Networks for Agriculture: The State-of-the-Art in Practice and Future Challenges. Comput. Electron. Agric. 2015, 118, 66-84. [CrossRef]

18. Sun, P.; Boukerche, A. Performance Modeling and Analysis of a UAV Path Planning and Target Detection in a UAV-Based Wireless Sensor Network. Comput. Netw. 2018, 146, 217-231. [CrossRef]

19. Kirichek, R.; Kulik, V. Long-Range Data Transmission on Flying Ubiquitous Sensor Networks (FUSN) by Using LPWAN Protocols. In Proceedings of the International Conference on Distributed Computer and Communication Networks, Moscow, Russia, 21-25 November 2016; Springer: Cham, Switzerland, 2016; pp. 442-453.

20. Wu, Q.; Zeng, Y.; Zhang, R. Joint Trajectory and Communication Design for Multi-UAV Enabled Wireless Networks. IEEE Trans. Wirel. Commun. 2018, 17, 2109-2121. [CrossRef]

21. Zeng, Y.; Xu, J.; Zhang, R. Energy Minimization for Wireless Communication with Rotary-Wing UAV. IEEE Trans. Wirel. Commun. 2019, 18, 2329-2345. [CrossRef]

22. Gili, P.; Civera, M.; Roy, R.; Surace, C. An Unmanned Lighter-than-Air Platform for Large Scale Land Monitoring. Remote Sens. 2021, 13, 2523. [CrossRef]

23. Jawad, H.M.; Nordin, R.; Gharghan, S.K.; Jawad, A.M.; Ismail, M. Energy-Efficient Wireless Sensor Networks for Precision Agriculture: A Review. Sensors 2017, 17, 1781. [CrossRef]

24. Piti, A.; Verticale, G.; Rottondi, C.; Capone, A.; Lo Schiavo, L. The Role of Smart Meters in Enabling Real-Time Energy Services for Households: The Italian Case. Energies 2017, 10, 199. [CrossRef]

25. Ilie-Ablachim, D.; Pǎtru, G.C.; Florea, I.M.; Rosner, D. Monitoring Device for Culture Substrate Growth Parameters for Precision Agriculture: Acronym: MoniSen. In Proceedings of the 15th RoEduNet Conference: Networking in Education and Research, Bucharest, Romania, 2 August 2016; pp. 1-7.

26. Gil-Lebrero, S.; Quiles-Latorre, F.J.; Ortiz-López, M.; Sánchez-Ruiz, V.; Gámiz-López, V.; Luna-Rodríguez, J.J. Honey Bee Colonies Remote Monitoring System. Sensors 2016, 17, 55. [CrossRef]

27. Cancela, J.J.; Fandiño, M.; Rey, B.J.; Martínez, E.M. Automatic Irrigation System Based on Dual Crop Coefficient, Soil and Plant Water Status for Vitis Vinifera (Cv Godello and Cv Mencía). Agric. Water Manag. 2015, 151, 52-63. [CrossRef]

28. Rao, Y.; Jiang, Z.H.; Lazarovitch, N. Investigating Signal Propagation and Strength Distribution Characteristics of Wireless Sensor Networks in Date Palm Orchards. Comput. Electron. Agric. 2016, 124, 107-120. [CrossRef]

29. Huircán, J.I.; Muñoz, C.; Young, H.; Von Dossow, L.; Bustos, J.; Vivallo, G.; Toneatti, M. ZigBee-Based Wireless Sensor Network Localization for Cattle Monitoring in Grazing Fields. Comput. Electron. Agric. 2010, 74, 258-264. [CrossRef]

30. Gutierrez, J.; Villa-Medina, J.F.; Nieto-Garibay, A.; Porta-Gandara, M.A. Automated Irrigation System Using a Wireless Sensor Network and GPRS Module. IEEE Trans. Instrum. Meas. 2014, 63, 166-176. [CrossRef]

31. Zhang, R.; Chen, L.; Guo, J.; Meng, Z.; Xu, G. An Energy-Efficient Wireless Sensor Network Used for Farmland Soil Moisture Monitoring. Proc. IET Conf. Publ. 2010, 2010, 2-6.

32. Navarro-Hellín, H.; Torres-Sánchez, R.; Soto-Valles, F.; Albaladejo-Pérez, C.; López-Riquelme, J.A.; Domingo-Miguel, R. A Wireless Sensors Architecture for Efficient Irrigation Water Management. Agric. Water Manag. 2015, 151, 64-74. [CrossRef]

33. Boon, M.A.; Drijfhout, A.P.; Tesfamichael, S. Comparison of a Fixed-Wing and Multi-Rotor UAV for Environmental Mapping Applications: A Case Study. Int. Arch. Photogramm. Remote Sens. Spat. Inf. Sci.-ISPRS Arch. 2017, 42, 47-54. [CrossRef]

34. Singh, J. Design and Evaluation of Unmanned Aerial System-Based Design and Evaluation of Unmanned Aerial System-Based Wireless Sensor Network for Irrigation Management Wireless Sensor Network for Irrigation Management, Lincoln; The University of NebraskaLincoln: Lincoln, NE, USA, 2021.

35. Singh, J.; Heeren, D.M.; Rudnick, D.R.; Woldt, W.E.; Bai, G.; Ge, Y.; Luck, J.D. Soil Structure and Texture Effects on the Precision of Soil Water Content Measurements with a Capacitance-Based Electromagnetic Sensor. Trans. ASABE 2020, 63, 141-152. [CrossRef]

36. Singh, J.; Ge, Y.; Heeren, D.M.; Walter-shea, E.; Neale, C.M.U.; Irmak, S.; Woldt, W.E.; Bai, G.; Bhatti, S.; Maguire, M.S. InterRelationships between Water Depletion and Temperature Differential in Row Crop Canopies in a Sub-Humid Climate. Agric. Water Manag. 2021, 256, 107061. [CrossRef]

37. Singh, J.; Heeren, D.M.; Ge, Y.; Bai, G.; Neale, C.M.U.; Maguire, S.; Bhatti, S. Sensor-Based Irrigation of Maize and Soybean in East-Central Nebraska under a Sub-Humid Climate 2021 Annual International Meeting. In Proceedings of the ASABE 2021 Annual International Meeting, American Society of Agricultural and Biological Engineers, St. Joseph, MI, USA, 17-20 July 2021; Volume 4, pp. 1-12.

38. Tzounis, A.; Katsoulas, N.; Bartzanas, T.; Kittas, C. Internet of Things in Agriculture, Recent Advances and Future Challenges. Biosyst. Eng. 2017, 164, 31-48. [CrossRef] 
39. Kour, V.P.; Arora, S. Recent Developments of the Internet of Things in Agriculture: A Survey. IEEE Access 2020, 8, 129924-129957. [CrossRef]

40. Mahmoud, M.S.; Mohamad, A.A.H. A Study of Efficient Power Consumption Wireless Communication Techniques/ Modules for Internet of Things (IoT) Applications. Adv. Internet Things 2016, 06, 19-29. [CrossRef]

41. Wixted, A.J.; Kinnaird, P.; Larijani, H.; Tait, A.; Ahmadinia, A.; Strachan, N. Evaluation of LoRa and LoRaWAN for Wireless Sensor Networks. In Proceedings of the 2016 IEEE SENSORS, Orlando, FL, USA, 30 October-3 November 2016; pp. 5-7. [CrossRef]

42. Reda, H.T.; Daely, P.T.; Kharel, J.; Shin, S.Y. On the Application of IoT: Meteorological Information Display System Based on LoRa Wireless Communication. IETE Tech. Rev. 2017, 35, 256-265. [CrossRef]

43. Lloret, J.; Sendra, S.; Ardid, M.; Rodrigues, J.J.P.C. Underwater Wireless Sensor Communications in the 2.4 GHz ISM Frequency Band. Sensors 2012, 12, 4237-4264. [CrossRef]

44. Nielsen, R.L. Grain Fill Stages in Corn. Corny News Network, Purdue University. 2017. Available online: http://www.king. corn/news/timeless/GrainFill.html (accessed on 9 February 2022).

45. Trihinas, D.; Agathocleous, M.; Avogian, K.; Katakis, I. FlockAI: A Testing Suite for Ml-Driven Drone Applications. Future Internet 2021, 13, 317. [CrossRef] 